\title{
Analysis of the Apartment Market in Behavioral Tax using PRMR and LRMR
}

\author{
Seong-hoon Jeong ${ }^{1}$, In-ho Choi ${ }^{2 *}$ \\ ${ }^{1}$ Associate professor in Dept. of Economics \& amp; International Trade, Daegu \\ Catholic University, Daegu city, 384-30, South Korea \\ ${ }^{2}$ Professor in Dept. of Real Estate, Namseoul University, Cheonan city, 331-707, \\ South Korea \\ ${ }^{1}$ James1101@cu.ac.kr, ${ }^{2}$ landchoi@nsu.ac.kr
}

\begin{abstract}
This study analyzed the PRMR and LRMR of the apartment market. The data were collected from January 2006 to June 2014. The trade data of 360 apartments were used. Each data is analyzed for 60 days before and after the implementation date; Before 60 days means -60 days from the implementation to -1 day, and after 60 days means +1 day from the implementation to +60 days. These data shows a statistical significance, which is calculated through the statistical analysis. The result says that the permanent decrease in the acquisition tax rate increased the profit realization of the profit investors. And the apartment owner do not realize loss often because the apartments are used for a living place. In other words, it is considered that the implementation of other policy of tax increase except the third acquisition tax increase led investors' cognitive bias to decrease that had been existed.
\end{abstract}

Keywords: PRMR(Profit Real Estate Maximized Potential Rate of Profit), LRMR(Loss Real Estate Maximized Potential Rate of Loss), MPRP(Maximized Potential Rate of Profit in Real Estate Price Index), Behavioral Tax, apartment market

\section{Introduction}

Jung and park (2009) did an empirical research on the vitalization of real estate selling, conducting the comprehensive real estate holding tax and the heavy tax policy of capital gains tax for the multiple-house owners. The comprehensive real estate holding tax[1] and heavy tax policy of capital gains tax[3] for the multiple-house owner would increase the burdens for speculation holders[4]. So, the speculation holders consider various ways to reduce the holing tax such as the comprehensive real estate holding tax and heavy tax policy of capital gains tax for multiple-house owner[5].

\section{Research model and established hypothesis using PRMR and LRMR}

To analyze PRMR[6] and LRMR[7] of real estate using this model, a fixed standard period is needed to figure out the potential profit or potential loss[8]. The two types of fixed standard period are used; six months and 1 year[8]. These are used to estimate the PRMR and LRMR of real estate. For example, buyer A purchased the house that is located in Gangnam district, Seoul,

Article history:

Received (February 17, 2019), Review Result (May 9, 2019), Accepted (August 12, 2019) 
and paid 300 million won in January 2012. In June 2012, buyer A sold this house for 400 million won, and then buyer A got a profit of 100 million won. In this case, the PRMR can be calculated based on 6 months using table 2-1. Also, buyer B purchased a house which located Yongsan district, Seoul, and paid 200 million won in January 2012. But, buyer B got a loss when buyer sold the house for 150 million won at June 2012. So, the LRMR of buyer B can be calculated.

Table 1. Example of Index of real estate price for PRMR, LRMR

\begin{tabular}{|c|c|c|}
\hline Time & $\begin{array}{c}\text { Index of Real estate price } \\
\text { Gangnam, Seoul }\end{array}$ & $\begin{array}{c}\text { Index of Real estate price } \\
\text { Yongsan, Seoul }\end{array}$ \\
\hline Jan-12 & 100 & 98 \\
\hline Feb-12 & 102 & 99 \\
\hline Mar-12 & 103 & 98 \\
\hline Apr-12 & 102 & 96 \\
\hline May-12 & 105 & 99 \\
\hline Jun-12 & 106 & 100 \\
\hline Jul-12 & 109 & 98 \\
\hline Aug-12 & 110 & 99 \\
\hline Sep-12 & 111 & 102 \\
\hline Oct-12 & 108 & 101 \\
\hline Nov-12 & 109 & 97 \\
\hline Dec-12 & 110 & 96 \\
\hline Jan-13 & 112 & 98 \\
\hline Feb-13 & 109 & 102 \\
\hline
\end{tabular}

* This data composed randomize number to explain the example.

$P R M R=\sum_{t=1}^{n} \frac{M P R P}{R R P+M P R P}, L R M R=\sum_{t=1}^{n} \frac{M P R L}{R R L+M P R L}$ PRMR: Profit Real Estate Maximized Potential Rate of Profit. LRMR: Loss Real Estate Maximized Potential Rate of Loss. MPRP: Maximized Potential Rate of Profit in Real Estate Price Index. MPRL: Maximized Potential Rate of Loss in Real Estate Price Index. RRP: Realized Rate of Profit. RRL: Realized Rate of Loss

First of all, this paper should calculate the realize return rate of buyer $\mathrm{A}(\mathrm{RRP})$ to product PRMR of buyer A. The RRP of buyer A is $33 \%$, which is divided by the transfer marginal profit. Next, MPRP (maximized potential rate of profit in real estate price index) of buyer A is used to maximize rate of return which ranges from June 2012 to Dec 2012; basis on standard term. MPRP of buyer A shows 4.72\%, which is the result value of (111-106) /106; the land price index 111 is a maximized index in September, 2012, and the land price 106 is standard.

Therefore, PRMR shows 0.87, which divides RRP (33\%) by the sum of RRP (33\%) and MPRP (4.72\%). The other hands, this paper should calculate the realized return rate of buyer B (RRL) to product LRMR of buyer B. In case of buyer B, the house trade made loss; - 50 million won, which is the result value of purchase price (200 million won) minus sold price (150 million won). The RRL of buyer B shows $-25 \%$.

The maximized potential rate of loss (MPRL) in real estate price index uses the lowest indices from June 2012 to Dec 2012. Therefore, MPRL is $-4.00 \%$, which used 96 in December, 2012. LRMR of buyer B is 0.862 , which is the result value of RRL (-25\%) divided by the sum of RRL (-25\%) and MPRL (-4.00\%). 


\section{Analysis of the apartment market after the tax rate change 3.1PRMR and LRMR after the tax rate increase}

The result from the analysis on the cognitive bias of the investors in apartment market using PRMR of profit real estate and the LRMR of the loss real estate says that the investors of the apartment market earned the potential profit. Also, the LRMR of the loss real estate appeared after the second acquisition tax rate increase.

However, it was not proper to compare because of the lack data on the prior loss realization frequency.

Table 2. Analysis on the increase of the acquisition tax rate and transfer income tax rate using PRMR-LRMR

\begin{tabular}{|c|c|c|c|c|c|c|c|}
\hline \multirow{2}{*}{$\begin{array}{l}\text { An implementation } \\
\text { date }\end{array}$} & \multirow{2}{*}{$\begin{array}{l}\text { Segregation of } \\
\text { before or after } \\
\text { implementation }\end{array}$} & \multicolumn{3}{|c|}{6 months } & \multicolumn{3}{|c|}{12 months } \\
\hline & & PRMR & LRMR & DIFF & PRMR & LRMR & DIFF \\
\hline \multirow{2}{*}{$\begin{array}{l}\text { 2011-01-01 } \\
\text { (First transfer } \\
\text { income taxes } \\
\text { increased) }\end{array}$} & \begin{tabular}{|l|} 
Before \\
\end{tabular} & 0.644 & 0 & 0.644 & 0.716 & 0 & 0.716 \\
\hline & After & 0.421 & 0 & 0.421 & 0.504 & 0 & 0.504 \\
\hline \multirow{2}{*}{$\begin{array}{c}2012-01-01 \\
\text { (Second transfer } \\
\text { income taxes } \\
\text { increased) }\end{array}$} & & 0.007 & 0 & 0.007 & 0.007 & 0 & 0.007 \\
\hline & After & 0.007 & 0.176 & -0.169 & 0.007 & 0.249 & -0.242 \\
\hline \multirow{2}{*}{$\begin{array}{c}2013-01-01 \\
\text { (Second acquisition } \\
\text { taxes increased) }\end{array}$} & Before & 0 & 0.062 & -0.062 & 0.007 & 0.077 & -0.07 \\
\hline & After & 0.009 & 0.086 & -0.077 & 0.084 & 0.095 & -0.011 \\
\hline \multirow{2}{*}{$\begin{array}{c}\text { 2013-07-01 } \\
\text { (Third acquisition } \\
\text { taxes increased) }\end{array}$} & Before & 0.071 & 0.095 & -0.024 & 0.193 & 0.095 & 0.098 \\
\hline & After & 0.163 & 0.026 & 0.138 & 0.244 & 0.052 & 0.191 \\
\hline Statistical test & $\begin{array}{c}6 \text { month } \\
\text { chi square }\end{array}$ & $41.362^{\circ}$ & \multicolumn{3}{|c|}{12 month chi square } & \multicolumn{2}{|c|}{$32.191^{\cdots}$} \\
\hline
\end{tabular}

The data are collected from January 2006 to June 2014. The trade data of 360 apartments are used. Each data is analyzed for 60 days before and after the implementation date; Before 60 days means -60 days from the implementation to -1 day, and after 60 days means +1 day from the implementation to +60 days. These data shows a statistical significance, which is calculated through the statistical analysis.

***: Significant level is less than 0.01, **: Significant level is less than 0.05 , *: Significant level is less than 0.1

At the first increase of acquisition tax rate in 6 months analysis, PRMR is calculated at 0.644. However, after the implementation, PRMR is calculated at 0.422, which can be estimated that the investors show more desirable investment behavior.

In case of the investors who sold before the increase of the tax rate, it is caused by the rapid reaction to a negative signal of tax rate, which is ended up with an incomplete earning of real estate. Also, the loss real estate investors reacted to the risk in more aversive way, which is ended up with a loss that could be avoided.

For the second transfer income tax rate increase, PRMR of before and after the increase are calculated at 0.007 , which shows no change of the investors' potential profit due to the increase 
of the acquisition tax rate and the second transfer income tax rate increase. For the PRMR of the second acquisition tax rate increase occurred January $1^{\text {st }} 2013$, it is calculated at 0.000 . Therefore, it is verified that the PRMR increases after the increase of the acquisition tax rate increase.

However, LRMR of loss real estate increased from 0.062 to 0.086 , which increases the potential loss of loss real estate investors. This means that the investors with loss trade in a desirable way after the increase of acquisition tax rate, and the increase affect the careful trade of the loss investors.

On the other hand, for the third increase of July $1^{\text {st }}, 2013$, PRMR was increase from 0.071 to 0.163 different from the usual cases, which is similar to what happened in the real estate market. In other words, the 8.28 plan not have little effect on the investors. The third increase which was a temporary policy ended up with a rapid selling remaining a potential profit due to the uncertainty caused by the frequent changes.

However, it affect positively to the loss real estate investors to sell without a potential loss, which is caused by the anxiety from the frequent changes of the policy. The similar results can be seen in the 1 year term analysis of PRMR and LRMR.

\subsection{PRMR and LRMR after the tax rate decrease}

In this analysis, it would be reviewed how tax policy change can affect investor's investment psychology, using PRMR and LRMR before and after the decrease acquisition tax and transfer income tax.

The result of analysis of first decrease transfer income tax, 6 month standard of PRMR before the decrease of transfer income tax is 0.037 , and 1 year standard of it is 0.112 and after the transfer income tax decrease implementation is 0.182 (6 month standard) and 0.352 ( 1 year standard).

In addition, LRMR is 0.000 (6 month and 1year standard) is calculated. It means that a big potential profit is occurred to investors who had profit real estate. It can be judged that the disadvantageous investment behavior occurs after the implementation. The reason of these phenomena might be the financial crisis in 2008 and the promotion of real estate trading. This result is like the real estate market's result.

Next before the decrease of second transfer income tax of PRMR is 0.450 (6 month), 0.564 (1 year). After the decrease, PRMR is declined as 0.176 (6 month) and 0.282 (1 year). LRMR is 0 in before and LRMR is 0.323 (6 month) and 0.349 ( 1 year) after the decrease. The reason of these phenomena might be the apartments are used for a living place. So, the trader do not realized losses.

In case of decrease acquisition tax, there were 5 times of decrease until now. However, the first and fifth decrease was not enough for analysis. So, second, third, and fourth decrease were analyzed. According to the result of analysis of second acquisition tax decrease, before the decrease PRMR value are 0.369 (6 month), 0.427 (1 year).

But, after the decrease, PRMR value are 0.352 (6 month), 0.383 (1 year). It means that the potential profit of investors who had profit real estate was declined. This is because DTI was partially reinforced in April 2011, after the decrease, investors' trades were limited compared than before the DTI plans that was similar to the real estate market results. The limit of DTI made investors who had profit real estate trade carefully.

The PRMR before the decrease was lower than the PRMR after decrease value. The third decrease implementation was similar to second decrease; before implementation, PRMR is 0.000 (6 month and 1year standard) calculated. 
However, after the decrease PRMR value are 0.006 (6 month), 0.162 (1 year). It means that the investors did realized profits and losses. When the fourth acquisition tax decreases, PRMR value are 0.120 (6 month), 0.195 (1 year) and after the decrease PRMR value are 0.009 (6 month), 0.030 (1 year). And the LRMR value are 0.067 (6 month), 0.068 (1 year), after the decrease LRMR is 0.000 (6 month and 1year standard) calculated.

Table 3. Analysis on the decrease of the acquisition tax rate and transfer income tax rate using PRMR-LRMR

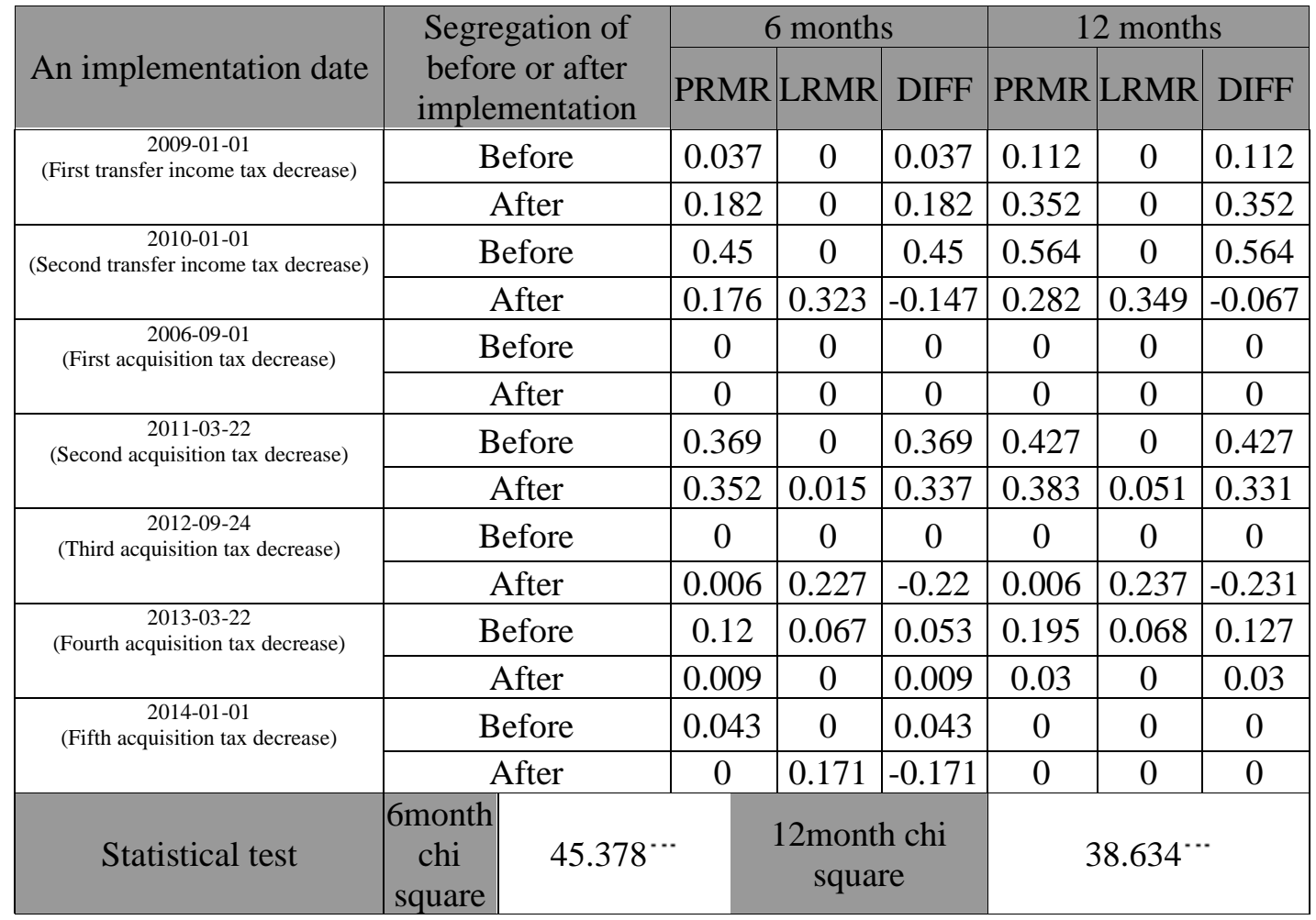

The data are collected from January 2006 to June 2014. The trade data of 360 apartments are used. Each data is analyzed for 60 days before and after the implementation date; Before 60 days means -60 days from the implementation to -1 day, and after 60 days means +1 day from the implementation to +60 days. These data shows a statistical significance, which is calculated through the statistical analysis.

***: Significant level is less than 0.01, **: Significant level is less than 0.05 , *: Significant level is less than 0.1

It can be judged that the desirable investment behavior occurs after the implementation. It means that the permanent acquisition tax decrease policy make increased investors behavior which realized profits.

\section{Conclusion}

This study analyzed the PRMR and LRMR of the apartment market. The result says that the permanent decrease in the acquisition tax rate increased the profit realization of the profit investors. And the apartment owner do not realize loss often because the apartments are used for a living place. In other words, it is considered that the implementation of other policy of tax 
increase except the third acquisition tax increase led investors' cognitive bias to decrease that had been existed.

\section{References}

[1] Cloyd, C. Bryan, Brian C. Spilker., 2000, "Confirmation bias in tax information search: A comparison of law students and accounting students." Journal of the American Taxation Association, Vol.22, No.2, pp.60-71 (2000). DOI: 10.2308/jata.2000.22.2.60

[2] Colin, Camerer, Loewenstein George, 2004, "Behavioral economics: Past, present, future". Princeton, Princeton University Press (2004).

[3] Collins, Julie H., Kemsley, Deen, "Capital Gains and Dividend Taxes in Firm Valuation: Evidence of Triple Taxation. " Accounting Review. Vol. 75 Issue 4, pp. 405-427 (2000) DOI: 10.2308/accr.2000.75.4.405

[4] Collins, Julie H., Kemsley, Deen., 2000, "Capital Gains and Dividend Taxes in Firm Valuation: Evidence of Triple Taxation. " Accounting Review, Vol. 75 Issue 4, pp. 405-427 (2000). DOI: 10.2308/accr.2000.75.4.405

[5] Dai. Zhonglan., Maydew Edward, Shackelford Douglas A., Zhang, Harold H., 2008, "Capital Gains Taxes and Asset Prices: Capitalization or Lock-in?". The Journal of Finance. Vol. 63, No.2, pp.709-742 (2008). DOI: 10.1111/j.1540-6261.2008.01329.x

[6] Elffers, Henk, Henry SJ Robben, Dick J. Hessing, 1992, "On measuring tax evasion." Journal of economic psychology 13.4 pp.545-567 (1992). DOI: 10.1016/0167-4870(92)90011-U

[7] Engelhardt, Gary V. 2003, "Nominal loss aversion, housing equity constraints, and household mobility: evidence from the United States." Journal of Urban Economics, Vol.53, No.1, pp.171-195 (2003). DOI: 10.1016/S0094-1190(02)00511-9

[8] Eugene F. Fama, 1970 "Efficient capital markets: A review of theory and empirical work*." The Journal of Finance, 25.2, pp.383-417 (1970). DOI: 10.1111/j.1540-6261.1970.tb00518.x

\section{Authors}

\section{Main Author's Name : Seong-hoon Jeong}

Associate professor in Dept. of Economics \&amp; International Trade, Daegu Catholic University, Daegu city, 384-30, South Korea.

E-mail : James1101@cu.ac.kr

\section{Corresponding Author's Name : In-ho Choi}

professor in Dept. of Real Estate, Namseoul University, Cheonan city, 331-707, South

Korea, E-mail :landchoi@nsu.ac.kr 